\title{
Production of Xanthan Gum by Xanthomonas Campestris CCT 13951 Submerged Fermentation on hydrolysed agroindustrial by-products
}

Joice Correia Santos

Instituto Federal de Educacao Ciencia e Tecnologia de Sergipe

Diego de Freitas Coêlho ( $\nabla$ diegofcoelho@gmail.com )

Universidade Federal de Sergipe https://orcid.org/0000-0002-2123-5891

Elias Basile Tambourgi

Universidade Estadual de Campinas

Gabriel Francisco Da Silva

Universidade Federal de Sergipe

Roberto Rodrigues Souza

Universidade Federal de Sergipe

\section{Research Article}

Keywords: xanthan gum, Xanthomonas campestris, cheese whey, passion fruit peel, agroindustrial residues

Posted Date: February 18th, 2021

DOI: https://doi.org/10.21203/rs.3.rs-158198/v1

License: (c) (i) This work is licensed under a Creative Commons Attribution 4.0 International License. Read Full License 


\section{Production of Xanthan Gum by Xanthomonas Campestris CCT 13951 Submerged Fermentation on hydrolysed agroindustrial by- products}

Joice C. Santos ${ }^{1}$, Diego. F. Coelho ${ }^{2,}{ }^{*}$, Elias. B. Tambourgi ${ }^{3}$, Gabriel. F. da Silva ${ }^{4}$, Roberto R. Souza ${ }^{5}$

${ }^{1}$ Department of Chemical Engineering, Federal University of Sergipe, São Cristóvão, Brazil. joicecorreia@yahoo.com

${ }^{2}$ Chemical Engineering School, Department of Chemical Systems Engineering, State University of Campinas, Campinas, Brazil.

diegofcoelho@gmail.com

${ }^{3}$ Chemical Engineering School, Department of Chemical Systems Engineering, State University of Campinas, Campinas, Brazil.

eliastam@feq.unicamp.br

${ }^{4}$ Department of Oil and Gas, Federal University of Sergipe, São Cristóvão, Brazil.

gabriel@ufs.br

${ }^{5}$ Department of Chemical Engineering, Federal University of Sergipe, São Cristóvão, Brazil. rrsouza@ufs.br

*Corresponding author:

Diego de Freitas Coêlho

Chemical Engineering School, State University of Campinas, Campinas, Brazil.

Av. Albert Einstein, 500 - Cidade Universitária, Campinas - SP, 13083-852

Telephone: +55193788 3952 / Fax: +55 1937883894 .

E-mail: diegofcoelho@gmail.com

ORCID: https://orcid.org/0000-0002-2123-5891 


\begin{abstract}
Xanthan is a natural polymer often obtained through fermentative processes using Xanthomonas, which remarkable properties - including biocompatibility, biodegradability, and non-toxicity - fit a myriad of industrial applications. The aim of this study was to evaluate the influence of different alternative fermentable substrates derived from agro-industrial waste (cheese whey and passion fruit peel), the production and rheological properties of the gum. The fermented substrate composition had a strong impact on production $\left(8.15-14.81 \mathrm{~g} \cdot \mathrm{L}^{-1}\right)$ and apparent viscosity (31.9-510 $\mathrm{mPa} . \mathrm{s})$. The maximum xanthan gum production was observed after $72 \mathrm{~h}$ using cheese whey and passion fruit peel acid hydrolysate supplemented with $\mathrm{K}_{2} \mathrm{HPO}_{4}(\mathrm{AH}: \mathrm{W}-\mathrm{Phosphate})$. However, the maximum viscosity was found for medium without supplementation (AH:W), twice the value of the samples supplemented with phosphate. All solutions were highly pseudoplastic. This study provides a cost-effective solution for the reusing of cheese whey and passion fruit peel and possible low-cost approach for xanthan production.
\end{abstract}

Keywords: xanthan gum, Xanthomonas campestris, cheese whey, passion fruit peel, agroindustrial residues 


\section{Introduction}

Xanthan, a biopolymer with outstanding rheological properties, is the most commercially produced industrial gum and usually obtained through fermentation by Xanthomonas campestris. It was discovered in the 1950s at the Northern Regional Research Laboratories (NRRL) of the United States Department of Agricultures (28).

The biopolymer is extensively used as thickening or stabilizing agent in the food, pharmaceutical, and oil recovery industries. Xanthan gum $(\mathrm{XG})$ is known for its unique rheological properties - pseudoplastic behaviour - and physico-chemical characteristics, such as high viscosity at low shear, shear thinning, stability over a broad range of temperature and $\mathrm{pH}$, high resistance to shear degradation in aqueous solutions, as well as its biodegradable and non-toxicity (22).

Commercial XG is currently produced through fermentation using glucose and sucrose, and available in the market at high prices (US\$ 4000-5000/ton) (23). Thus, investigations regarding low-cost substrates that could be used to produce XG through fermentation are especially important because they may support the development of a bioprocess with the potential to reduce drastically its production costs and replace synthetic chemicals as standard feedstock.

Several different agroindustrial residues have been used as source of nutrients for the fermentation medium to produce xanthan, such as citrus waste (3); olive-mill waters (1), cheese whey (15), raw cassava starch (19), tapioca pulp (14), residue of apple juice (11), orange peel (26), palm date (29), shrimp shell (10) and sugarcane (15). However, additional nutrients are still required, as shown by Salah et al. (29). In their research, $\mathrm{K}_{2} \mathrm{H}_{2} \mathrm{PO}_{4}, \mathrm{MgSO}_{4},\left(\mathrm{NH}_{4}\right)_{2} \mathrm{SO}_{4}$, citric acid, $\mathrm{H}_{3} \mathrm{BO}_{3}, \mathrm{ZnCl}_{2}, \mathrm{FeCl}_{3}$ e $\mathrm{CaCO}_{3}$ were added to the medium when palm fruit waste was used as the alternative substrate, which improved the xanthan gum production but 
unfortunately increased its cost. Thus, the utilization of low-cost material as sole substrate is desirable, once their use can help to reduce the environmental impacted associated with their disposal (2).

Whey is the aqueous fraction of milk generated as by-product of cheese manufacturing. This by-product represents about $90 \%$ of the milk volume and retains $55 \%$ of milk nutrients. Among the most abundant of these nutrients are lactose $(4.5-5 \% \mathrm{~m} / \mathrm{v})$, soluble proteins $(0.6-$ $0.8 \% \mathrm{~m} / \mathrm{v})$, lipids $(0.4-0.5 \% \mathrm{~m} / \mathrm{v})$ and mineral salts $(8-10 \%$ of dried extract $)(32,13)$. Approximately $50 \%$ of worldwide whey production is not treated and as a result a very large amount of material with potential value is wasted (8).

In Brazil, another agroindustrial residue with excellent fermentative potential is the passion fruit peel, a material rich in macronutrients and micronutrients (21). During the fruit processing for juice extraction, thousands of tons of peels and seeds are produced, accounting for approximately $70 \%$ of the total fruit weight (6). As Brazil is the world leader in the production of yellow passion fruit, exceeding 694,000 tonnes in 2015 (17), the disposal of this residue becomes both an environmental problem and a colossal waste of resources, since it is basically composed by carbohydrates, proteins and pectin (5).

Therefore, the use of agroindustrial wastes, from both economic and environmental point-of-views (2) is highly desirable, since it contribute towards the development of sustainable processes and reduce the production cost of several valuable bioproducts.

In this context, this study aimed to evaluate the use of agroindustrial residues (cheese whey and passion fruit peel) as alternative substrates in the production of XG by Xanthomonas campestris CCT 13951 and its effects on the gum's rheological properties.

\section{Material and Methods}




\subsection{Chemicals}

All chemicals used in this work were of analytical grade and were obtained from Merck (Darmstadt, Germany) and Sigma (St. Louis, MO, USA).

\subsection{Chemical Composition of the Substrate}

Substrate humidity, total protein, and ash contents were determined according to Horwitz (16), while the total lipid content was determined as described by Bligh and Dyer (4). Total carbohydrate content was calculated by difference, subtracting the humidity, protein, lipid, and ash fractions from the sample total mass. Total reducing sugars were quantified by the IAL method (24).

\subsection{Microorganism}

Xanthomonas campestris CCT 13951 was acquired from the Collection of the Tropical Cultures André Tosello Foundation (Campinas - São Paulo - Brazil). The strain was cultured on yeast malt $(\mathrm{YM})$ medium containing $(\mathrm{m} / \mathrm{v}) 0.3 \%$ yeast extract, $0.3 \%$ malt extract, $0.5 \%$ bacteriological peptone, $1.0 \%$ glucose. The maintaining culture was held in YMA, being added $2.0 \%$ agar to the standard YM. The mediums were sterilized at $121^{\circ} \mathrm{C}$ for 15 minutes. The inoculum was prepared by growing the strain in a yeast malt (YM) medium at $28^{\circ} \mathrm{C}$ and 150 rpm for 24 hours.

\subsection{Substrate preparation}

The cheese whey was provided by the Federal Institute of Sergipe (São Cristóvão, SE, Brazil). Upon collection, the cheese whey was pretreated at $90^{\circ} \mathrm{C}$ for 5 minutes, followed by filtration using cheese cloth and stored at $-5^{\circ} \mathrm{C}$ until its use.

Yellow passion fruit (Passiflora edulisf. flavicarpa L.) was purchased from the local fruit market in Aracaju, Sergipe state, Brazil. The fruits were washed, cut and the pulp and seeds were removed. The peels were washed in tap water to remove the adhering pulp and soluble sugars. The passion fruit peels with mesocarp were ground by a mechanical mixer. 
The obtained passion fruit extract was subjected to either acid or basic hydrolysis in a 1:10 ratio (grams of residue per gram of water). Acid hydrolysis was performed by adjusting the $\mathrm{pH}$ to $2.0 \mathrm{using}$ a $2 \mathrm{~mol} \cdot L^{-1} \mathrm{H}_{2} \mathrm{SO}_{4}$ solution, and the basic hydrolysis by adjusting the $\mathrm{pH}$ to 7.0 using a $2 \mathrm{~mol} \cdot \mathrm{L}^{-1} \mathrm{NaOH}$ solution. Both acid and basic suspensions were autoclaved at $121^{\circ} \mathrm{C}$ for 15 minutes and subsequently filtered using a 102 qualitative filter paper, to remove insoluble solids. The acid and basic hydrolysed extracts were labelled as $\mathrm{AH}$ and $\mathrm{BH}$, respectively.

\subsection{Fermentation}

Both hydrolysed extracts - $\mathrm{AH}$ and $\mathrm{BH}$ - were diluted using cheese whey (W) in a 1:3 ratio (v/v), reaching a final concentration of $45 \mathrm{~g} \cdot \mathrm{L}^{-1}$ of total reducing sugars.

Fermentation substrates consisted of both hydrolysates with or without supplementation (A:H and B:H). Supplemented mediums were prepared by mixing the whey-diluted hydrolysate $(\mathrm{AH}: \mathrm{W}$ and $\mathrm{BH}: \mathrm{W})$ with $0.2 \%$ potassium phosphate $(\mathrm{AH}: \mathrm{W}$ - Phosphate and BH:W - Phosphate) or with 1\% sucrose (samples AH:W - Sucrose and BH - Sucrose). Each bioreactor consisted of a $250 \mathrm{~mL}$ Erlenmeyer flask containing $100 \mathrm{~mL}$ of medium, which had its $\mathrm{pH}$ adjusted to 7.0 and was autoclaved at $121^{\circ} \mathrm{C}$ for 15 minutes.

The medium was inoculated with $20 \%(\mathrm{v} / \mathrm{v})$ X. campestris culture. The fermentation was carried out for 96 hours at $30^{\circ} \mathrm{C}$ and $250 \mathrm{rpm}$ on an orbital shaker. Samples were collected every 24 hours to observe XG production and the conversion of total reducing sugars.

\subsection{Recovery of Xanthan Gum}

Samples collected during the fermentation were autoclaved and then centrifuged at $9,625 \mathrm{xG}$ for $15 \mathrm{~min}$ to remove the Xanthomonas campestris biomass. The $\mathrm{XG}$ was precipitated from the supernatants by adding ethanol $96 \%(3: 1 \mathrm{v} / \mathrm{v})$ to the fermentation broth. The solutions were maintained at $4^{\circ} \mathrm{C}$ during $24 \mathrm{~h}$ and re-centrifuged. The precipitate was collected and dried 
at $50^{\circ} \mathrm{C}$ until constant weight, which allowed to calculate the $\mathrm{XG}$ concentration (in grams of gum per litre of culture medium) (10).

\subsection{Rheology of Xanthan Gums}

The rheological behaviour of the XGs produced by the X. campestris ATCC 13951 was evaluated by apparent viscosity $(\mathrm{mPa} \cdot s)$ using a rheometer (Rheomat RM 300, Lamy Rheology, France) equipped with a concentric cylinder geometry coupled to a water bath. The apparent viscosities of the samples were determined at $25^{\circ} \mathrm{C}$ and shear rates from $25 \mathrm{~s}^{-1}$ to 1000 $\mathrm{s}^{-1}$. The XG solutions were prepared by adding $3 \%(\mathrm{~m} / \mathrm{v}) \mathrm{XG}$ in distilled water. The relationship between the shear rate and the viscosities for the XG solutions was described by the Ostwaldde-Waele kinetic model, as shown below.

$$
\mu=K(\gamma)^{-1}
$$

Where $\mu$ is the apparent viscosity, $\gamma$ is the shear rate, $\mathrm{k}$ is the consistency index - i.e. the viscosity measured at a shear rate of $1 \mathrm{~s}^{-1}$, and $n$ is the flow behaviour index. For shear thinning or pseudoplastic media, $\mathrm{n}<1$. Eq. (1) assumes an absence of yield stress.

The pseudoplastic behaviour of the $\mathrm{XG}$ solution was confirmed by fitting the experimental data to the Oswald-de-Waele model, and thus estimating the values of the consistency index $(K)$, flow index $(n)$, and correlation coefficients $\left(\mathrm{R}^{2}\right)$ for each $\mathrm{XG}$ solution.

\subsection{Spectroscopy of Fourier transform infrared (FTIR)}

FT-IR analysis were performed with a Thermo Scientific Nicolet iS10 for all samples commercial and produced by the authors - in the $400 \cdot \mathrm{cm}^{-1}$ to $4000 \cdot \mathrm{cm}^{-1}$ wavelength range using a $4 \mathrm{~cm}^{-1}$ step and 64 scans per sample. Three spectra were acquired sequentially for each sample. These spectra were processed and analysed using OriginPro 8.0 software.

\section{Results and discussion}




\subsection{Agroindustrial Waste Composition and Proximate}

As shown in Table 1, both cheese whey residue and passion fruit peels residues have similar protein and carbohydrate composition but vary significatively in the lipid and inorganic fractions. The centesimal composition of the fermentable substrates is essential to study the XG production, given that nutrients and micronutrients influence both cell growth of Xanthomonas bacteria and XG production during the fermentation (9). Druzian and Pagliarini (11) have proved that most of the carbohydrates present on passion fruit peels are in fact pectin, a galacturonic acid polymer that can be broken down by Xanthomonas to its monomers and then be used as a source of carbon during fermentation. Bilanovic et al. (3) investigated the use of citrus waste as a low-cost substrate for XG production by converting it to pectin, hemicelluloses, and cellulose fractions. The results also proved that the pectin present in the fermentation medium was consumed by the microorganism and subsequently converted to XG.

\section{[TABLE 1]}

Xanthan Gum has been produced through fermentation from several alternative substrates, such as cassava (31), green coconut (9), shrimp shell (10), and sugarcane (33), only by supplementing the fermentation with urea $(0.01 \% \mathrm{~m} / \mathrm{v})$ and $\mathrm{K}_{2} \mathrm{HPO}_{4}(0.1-2.0 \% \mathrm{~m} / \mathrm{v})$, resulting in lower production costs.

Kalogiannis et al. (18) studied the XG production by X. campestris ATCC 1395 using pre-treated molasses from sugar beet as carbon source, supplemented with $\mathrm{K}_{2} \mathrm{HPO}_{4}$, yeast extract, Triton 80 , and water. Addition of $\mathrm{K}_{2} \mathrm{HPO}_{4}$ to the medium had a significant positive effect on XG production. These studies indicated that the addition of phosphates enhanced XG production both because the medium was deficient in phosphates and because they act as a buffering agent, reducing the $\mathrm{pH}$ fluctuations. 


\subsection{Xanthan Gum Production}

Figure 1 shows the production of XG over time by X. campestris ATCC 13951 for both pre-treatment methods (acid hydrolysis and basic hydrolysis), as well as for mediums supplemented and with no supplementation. The supplementation of the medium and the pretreatment of extract had a strong effect on $\mathrm{XG}$ production, which ranged from $8.15 \mathrm{~g} \cdot \mathrm{L}^{-1}$ to $14.81 \mathrm{~g} \cdot \mathrm{L}^{-1}$

The acid-hydrolysis method reached higher XG production, even without supplementation, when compared to the other substrates. The maximum XG production $15 \mathrm{~g} \cdot \mathrm{L}^{-1}$ - was observed at $72 \mathrm{~h}$ of fermentation for an acid-hydrolysed pre-treated substrate supplemented with $\mathrm{K}_{2} \mathrm{HPO}_{4}(\mathrm{AH}: \mathrm{W}-$ Phosphate) (Fig.1A).

\section{[FIGURE 1]}

Gunasekar et al. (14) investigated the effect of the sulphuric acid concentration $(0.5 \%$, $2.5 \%$ and $5.0 \%)$ on xanthan fermentation. Maximum xanthan yield $\left(7.1 g \cdot L^{-1}\right)$ was obtained with $0.5 \%$ sulphuric acid pre-treatment. The authors observed that the acid hydrolysis caused the formation of inhibitory compounds and lowered the xanthan yield production. According to Klasson et al. (20), furfural, 5-hydroximethylfurfural and other furan derivatives are often present in the hydrolysate after acid pre-treatment of organic biomasses, especially, lignocellulose, cellulose and other similar materials.

This hypothesis is supported by Li et al. (23) during their study on the production of XG using kitchen waste as the sole substrate. The kitchen waste was pretreated by acid hydrolysis using $1.5 \%$ sulphuric acid at $121^{\circ} \mathrm{C}$ for $60 \mathrm{~min}$ but had no undesired effects due inhibitors formation.

Silva et al. (30) also evaluated the production of XG using cheese whey as substrate by two strains of Xanthan campestris, although the authors chose to supplement the fermentation medium with sucrose. The cheese whey:sucrose ratio and supplementation were investigated 
by a Central Composite Design (CCD), allowing the authors to place the $\mathrm{MgSO} 4 \cdot 7 \mathrm{H} 2 \mathrm{O}$ concentration and cheese whey: sucrose ratio as non-statistically significant $(\mathrm{p}<0.05)$ factors for the two strains tested. Nevertheless, a maximum XG production of $25 g \cdot L^{-1}$ was observed after $72 \mathrm{~h}$ using cheese whey as sole carbon source, $0.1 \%(\mathrm{~m} / \mathrm{v}), \mathrm{MgSO}_{4} \cdot 7 \mathrm{H} 2 \mathrm{O}$ and $2.0 \%$ $(\mathrm{m} / \mathrm{v})$ of $\mathrm{K}_{2} \mathrm{HPO}_{4}$.

After $72 \mathrm{~h}$ of fermentation, the concentration of $\mathrm{XG}$ in $\mathrm{AH}: \mathrm{W}-$ sucrose and $\mathrm{BH}: \mathrm{W}-$ Sucrose reached high values of $12.92 \mathrm{~g} \cdot \mathrm{L}^{-1}$ and $11.2 \mathrm{~g} \cdot \mathrm{L}^{-1}$, respectively. Although smaller than the best results found in the literature, the production of XG using both whey and passion fruit peel waste reached production yields that prove the potential of both residues as alternative substrate and its promising future.

Mesomo et al. (25) reported their success when producing XG by X. campestris $p v$. mangiferaeindicae IBSBF 1230 on a bioreactor operating at $28^{\circ} \mathrm{C}$, initial $\mathrm{pH} 7.2,390 \mathrm{rpm}$ agitation and aeration of $1.5 \mathrm{vvm}$. They obtained 36 g.L $\mathrm{L}^{-1}$ of $\mathrm{XG}$ employing cheese whey as carbon source, supplemented with $1 \mathrm{~g} . \mathrm{L}^{-1}$ magnesium sulphate, $20 \mathrm{~g} . \mathrm{L}^{-1}$ potassium phosphate. 
Figure 2 shows the effect of the supplementation of the medium and the pre-treatment on the total reducing sugar concentration and its conversion throughout the fermentation process. The concentration of total reducing sugar decreased gradually and nearly inversely proportionally correlated to the xanthan production. In all cases, Xanthomonas campestris CCT 13951 was able to convert over $70 \%$ of reducing sugars, which associated to XG production curves indicates that most of the reducing sugar was assimilated for the xanthan production.

\section{[FIGURE 2]}

Li et al. (23) reported that the reducing sugars conversion rate was rather low $(53.88 \%)$ and likely used for cell reproduction and respiration, whereas higher concentrations (higher than $50 \mathrm{~g} \cdot \mathrm{L}^{-1}$ ) of a carbon source could inhibit the formation of xanthan product.

\subsection{Rheological properties}

The Figure 3 shows the viscosity behaviour of the produced XGs according to the range of shear rate used during the rheological assay. The shear rate dependence of viscosity was fitted by the Ostwald-de-Walle model, according to Eq. (1). The parameters estimated by the Levenberg-Marquardt algorithm in Statistic 6.0 (Statoil Inc) are presented in Table 2.

\section{[TABLE 2]}

According to Garcia-Ochoa et al. (12) xanthan solutions have a non-Newtonian rheology, in which the apparent viscosity decreases as shear rate increases. One important property of XGs is the ability to modify the rheological behaviour of solutions. The rheological properties of XGs are mainly related to its chemical structure, molar mass, molecular arrangement and molecular bonding, which will vary according to the chosen microorganism and respective strain - as well as with the substrate used.

The highest viscosity value (510 mPa.s) was obtained for the gum from acid pretreatment and without supplementation (AH:W) at shear rate of $25 \mathrm{~s}^{-1}$, which is twice of those values obtained for samples supplemented with phosphate. 


\section{[FIGURE 3]}

Silva et al. (30) determined the apparent viscosity of XG using cheese whey as substrate by two strains of $X$. campestris. The viscosity obtained was about $60 \mathrm{mPa} . \mathrm{s}\left(25^{\circ} \mathrm{C}\right.$ and shear rate $12.5 \mathrm{~s}^{-1}$, solution $3 \%(\mathrm{w} / \mathrm{v})$. Being below the one found by this work, except for the sample acid pre-treatment and supplemented with sucrose (AH:W- Sucrose). Nitschke et al. (27) determined the apparent viscosity at $1 \%$ aqueous gum synthesized in whole medium cheese whey at a shear rate of $10 \mathrm{~s}^{-1}$ at $25^{\circ} \mathrm{C}$ and the final viscosity observed was about $9508 \mathrm{cP}$. Costa et al. (7) evaluated the yields of XGs produced from shrimp shell by three native strains of $X$. campestris, incubated at $28^{\circ} \mathrm{C}$ for 120 hours with agitation at $250 \mathrm{rpm}$ in a medium supplemented whit $\mathrm{K}_{2} \mathrm{HPO}_{4}$. Strain 1182 showed the highest yield (4.64 g.L $\left.\mathrm{L}^{-1}\right)$ and viscosity (48.53 mPa.s,), $0.5 \%$ aqueous $\mathrm{XG}$ solution, $25 \mathrm{~s}^{-1}$ and $25^{\circ} \mathrm{C}$ ), from the medium containing $10 \%$ $(w / v)$ of aqueous shrimp shell extracts.

The 3\% XG solutions obtained from the whey and passion fruit peel followed the model previously described, all the correlation coefficients $\left(\mathrm{R}^{2}\right)$ were close to 0.99 , independently of the fermentative medium. In all cases, the value for $n$ was smaller than unity - implying pseudoplastic behaviour - and ranging between 0.398 and 0.739 for the gum produced with acid pre-treatment, and between 0.488 and 0.545 for that obtained using alkaline pre-treatment.

While a comparison between XG production or its apparent viscosity could be easily provided, no method has been described in the literature that could consider both parameters during a process design or a product development. Therefore, the result variations observed throughout the literature are expected and a consequence of discrepancies in the strain used, the medium composition from different agroindustrial residues, and the fermentation conditions. 


\subsection{Spectroscopy of Fourier transform infrared (FTIR)}

Samples of commercial xanthan $(\mathrm{CX}), \mathrm{AH}: \mathrm{W}$ and $\mathrm{BH}: \mathrm{W}$ were analysed to identify the functional groups present in the structure of these biopolymers. The region studied included all the spectral bands located in the window between the wave numbers 400 and $4000 \mathrm{~cm}^{-1}$. Fig. 3 shows the infrared spectra of samples. Xanthan samples showed the presence of hydroxyl (13200 $\left.\mathrm{cm}^{-1}\right)$, carbonyl $\left(1400 \mathrm{~cm}^{-1}\right.$, carboxyl $\left(1600 \mathrm{~cm}^{-1}\right)$ e acetal groups $\left(1050 \mathrm{~cm}^{-1}\right)$. Fig. 4 shows that the infrared spectrum of the $\mathrm{CX}$ is remarkably like that obtained by $X$. campestris 13951 using the $\mathrm{AH}: \mathrm{W}$ and $\mathrm{BH}: \mathrm{W}$ substrates. The decrease in transmittance intensities observed throughout the spectra means an increase in the amount (per unit volume) of the functional group associated with the molecular bond, while a shift in peak position usually means that the electron distribution or hybridization state in the molecular structure has changed.

\section{[FIGURE 4]}

Xanthomonas Campestris CCT 13951 has proven to be able to produce xanthan gum using an agroindustrial hydrolysate - composed by passion fruit peel and cheese whey - as substrate. Both the substrate pre-treatment method and its supplementation showed significative effects on the xanthan gum production and its apparent viscosity.

The highest concentration of xanthan gum $15 \mathrm{~g} \cdot \mathrm{L}^{-1}$ was obtained after $72 \mathrm{~h}$ of fermentation and using an acid-hydrolysed substrate supplemented with $\mathrm{K}_{2} \mathrm{HPO}_{4}$. The maximum apparent viscosity observed in the study was $510 \mathrm{mPa} \cdot \mathrm{s}$ at $25^{\circ} \mathrm{C}$ and using $3 \%$ of a gum also produced using the acid-hydrolysed substrate, but with no supplementation, and which gum production was $12.38 \mathrm{~g} . \mathrm{L}^{-1}$. The results show that higher production yields are not correlated to the gum quality. The results obtained in this study, although preliminary, provide a projection of the potential of using fermentation substrates composed only by agroindustrial residues in the production of xanthan gum. 


\section{Declarations}

\subsection{Ethical Approval and Consent to Participate}

Not applicable. The manuscript does not contain data collected from humans or animals.

\subsection{Consent to Publish}

Not applicable. The manuscript does not contain any individual person's data.

\subsection{Authors Contributions}

JCS and RRS conceptualized the study. JCS performed the main experimental work, evaluated the dataset, and wrote the main text of the manuscript. EBT, GFS and DFC were involved in proofreading of the manuscript.

\subsection{Funding}

Authors would like to thank FAPITEC (Fundação de Apoio à Pesquisa e Inovação Tecnológica do Estado de Sergipe), CAPES (Coordenação de Aperfeiçoamento de Pessoal de Nível Superior), and CNPq (Conselho Nacional de Desenvolvimento Científico e Tecnológico) for the financial support.

\subsection{Competing Interests}

The authors declare that they have no known competing financial interests or personal relationships that could have appeared to influence the work reported in this paper.

\subsection{Availability of data and materials}

The datasets used during the current study are available from the corresponding author on reasonable request. 


\section{References}

1. Ahmed, P. M., Fernández, P. M., de Figueroa, L. I. and Pajot, H. F. (2019) Exploitation alternatives of olive mill wastewater: production of value-added compounds useful for industry and agriculture. Biofuel Research Journal, 6, 980-994.

2. Bhatia, L., Johri, S. and Ahmad, R. (2012) An economic and ecological perspective of ethanol production from renewable agro waste: a review. Amb Express, 2, 1-19.

3. Bilanovic, D., Shelef, G. and Green, M. (1994) Xanthan fermentation of citrus waste. Bioresour. Technol., 48, 169-172.

4. Bligh, E. G. and Dyer, W. J. (1959) A rapid method of total lipid extraction and purification. Can J Biochem Physiol, 37, 911-917.

5. Canteri, M. H., Scheer, A., Petkowicz, C., Ginies, C., Renard, C. and Wosiacki, G. (2010) Physicochemical composition of the yellow passion fruit pericarp fractions and respective pectic substances. J. Food. Nutr. Res., 49.

6. CÓRDOVA, K. R. V., GAMA, T. M. T. B., WINTER, C. M. G., NETO, G. K. and DE FREITAS, R. J. S. (2005) Características físico-químicas da casca do maracujá amarelo (Passiflora edulis Flavicarpa Degener) obtida por secagem. Boletim do Centro de Pesquisa de Processamento de Alimentos, 23.

7. Costa, L. A. d. S., Inomata Campos, M., Izabel Druzian, J., de Oliveira, A. M. and de Oliveira Junior, E. N. (2014) Biosynthesis of xanthan gum from fermenting shrimp shell: yield and apparent viscosity. Int. J. Polym. Sci.

8. da Silva Duarte, V., Carlot, M., Pakroo, S., Tarrah, A., Lombardi, A., Santiago, H., Corich, V. and Giacomini, A. (2020) Comparative evaluation of cheese whey microbial composition from four Italian cheese factories by viable counts and 16S rRNA gene amplicon sequencing. Int. Dairy J., 104656.

9. da Silva, J. A., Cardoso, L. G., de Jesus Assis, D., Gomes, G. V. P., Oliveira, M. B. P. P., de Souza, C. O. and Druzian, J. I. (2018) Xanthan Gum Production by Xanthomonas campestris pv. campestris IBSBF 1866 and 1867 from Lignocellulosic Agroindustrial Wastes. Appl. Biochem. Biotechnol., 186, 750-763.

10. de Sousa Costa, L. A., Inomata Campos, M., Izabel Druzian, J., de Oliveira, A. M. and de Oliveira Junior, E. N. (2014) Biosynthesis of xanthan gum from fermenting shrimp shell: yield and apparent viscosity. Int. J. Polym. Sci., 2014.

11. Druzian, J. I. and Pagliarini, A. P. (2007) Xanthan gum production by fermentation from residue of apple juice. Food Sci. Technol., 27, 26-31. 
12. Garcia-Ochoa, F., Santos, V., Casas, J. and Gómez, E. (2000) Xanthan gum: production, recovery, and properties. Biotechnol. Adv., 18, 549-579.

13. Guimarães, P. M., Teixeira, J. A. and Domingues, L. (2010) Fermentation of lactose to bio-ethanol by yeasts as part of integrated solutions for the valorisation of cheese whey. Biotechnol. Adv., 28, 375-384.

14. Gunasekar, V., Reshma, K., Treesa, G., Gowdhaman, D. and Ponnusami, V. (2014) Xanthan from sulphuric acid treated tapioca pulp: influence of acid concentration on xanthan fermentation. Carbohydr. Polym., 102, 669-673.

15. Habibi, H. and Khosravi-Darani, K. (2017) Effective variables on production and structure of xanthan gum and its food applications: A review. Biocatal. Agric. Biotechnol., 10, 130-140.

16. Horwitz, W. (2010) Official methods of analysis of AOAC International. Volume I, agricultural chemicals, contaminants, drugs/edited by William Horwitz. ed. AOAC International, Gaithersburg (Maryland).

17. IBGE. (2015) Produção Agrícola Municipal Anual. Instituto Brasileiro De Geografia e Estatística.

18. Kalogiannis, S., Iakovidou, G., Liakopoulou-Kyriakides, M., Kyriakidis, D. A. and Skaracis, G. N. (2003) Optimization of xanthan gum production by Xanthomonas campestris grown in molasses. Process Biochem., 39, 249-256.

19. Kerdsup, P., Tantratian, S., Sanguandeekul, R. and Imjongjirak, C. (2011) Xanthan production by mutant strain of Xanthomonas campestris TISTR 840 in raw cassava starch medium. Food Bioprocess Technol., 4, 1459-1462.

20. Klasson, K. T., Uchimiya, M., Lima, I. and Boihem Jr, L. (2011) Feasibility of removing furfurals from sugar solutions using activated biochars made from agricultural residues. BioResources, 6, 3242-3251.

21. Kliemann, E., De Simas, K. N., Amante, E. R., Prudêncio, E. S., Teófilo, R. F., Ferreira, M. M. and Amboni, R. D. (2009) Optimisation of pectin acid extraction from passion fruit peel (Passiflora edulis flavicarpa) using response surface methodology. Int. J. Food Sci. Tech., 44, 476-483.

22. Kreyenschulte, D., Krull, R. and Margaritis, A. (2014) Recent advances in microbial biopolymer production and purification. Crit. Rev. Biotechnol., 34, 1-15. 
23. Li, P., Li, T., Zeng, Y., Li, X., Jiang, X., Wang, Y., Xie, T. and Zhang, Y. (2016) Biosynthesis of xanthan gum by Xanthomonas campestris LRELP-1 using kitchen waste as the sole substrate. Carbohydr. Polym., 151, 684-691.

24. Lutz, I. A. (1985) Métodos químicos e físicos para análise de alimentos. Normas Analíticas do Instituto Adolfo Lutz, 1.

25. Mesomo, M., Silva, M. F., Boni, G., Padilha, F. F., Mazutti, M., Mossi, A., de Oliveira, D., Cansian, R. L., Di Luccio, M. and Treichel, H. (2009) Xanthan gum produced by Xanthomonas campestris from cheese whey: production optimisation and rheological characterisation. J. Sci. Food Agric., 89, 2440-2445.

26. Mohsin, A., Zhang, K., Hu, J., Tariq, M., Zaman, W. Q., Khan, I. M., Zhuang, Y. and Guo, M. (2018) Optimized biosynthesis of xanthan via effective valorization of orange peels using response surface methodology: A kinetic model approach. Carbohydr. Polym., 181, 793-800.

27. Nitschke, M., Rodrigues, V. and Schinatto, L. F. (2001) Formulação de meios de cultivo à base de soro de leite para a produção de goma xantana por X. Campestris C7L. Food Sci. Technol., 21, 82-85.

28. Palaniraj, A. and Jayaraman, V. (2011) Production, recovery and applications of xanthan gum by Xanthomonas campestris. J. Food Eng., 106, 1-12.

29. Salah, R. B., Chaari, K., Besbes, S., Ktari, N., Blecker, C., Deroanne, C. and Attia, H. (2010) Optimisation of xanthan gum production by palm date (Phoenix dactylifera L.) juice by-products using response surface methodology. Food Chem., 121, 627-633.

30. Silva, M. F., Fornari, R. C., Mazutti, M. A., de Oliveira, D., Padilha, F. F., Cichoski, A. J., Cansian, R. L., Di Luccio, M. and Treichel, H. (2009) Production and characterization of xantham gum by Xanthomonas campestris using cheese whey as sole carbon source. J. Food Eng., 90, 119-123.

31. Sujithra, B., Deepika, S., Akshaya, K. and Ponnusami, V. (2019) Production and optimization of xanthan gum from three-step sequential enzyme treated cassava bagasse hydrolysate. Biocatal. Agric. Biotechnol., 21, 101294.

32. Treu, L., Tsapekos, P., Peprah, M., Campanaro, S., Giacomini, A., Corich, V., Kougias, P. G. and Angelidaki, I. (2019) Microbial profiling during anaerobic digestion of cheese whey in reactors operated at different conditions. Bioresour. Technol., 275, 375-385. 
33. Vignesh, P., Arumugam, A. and Ponnusami, V. (2015) Modeling and steady state simulation: production of xanthan gum from sugarcane broth. Bioprocess Biosystems Eng., 38, 49-56. 


\section{Figure captions}

Figure 1: Effect of the supplementation of the medium and the pre-treatment of extract on xanthan gum production: acid hydrolysis (A) and alkaline hydrolysis (B).

Figure 2: Effect of the supplementation of the medium and the pre-treatment of extract on total reducing sugars and reducing sugar conversion: acid - hydrolysis (A and B) and alkaline hydrolysis (C and D).

Figure 3: Effect of shear rate on the viscosity of the xanthan (A) acid pre-treatment and (B) alkaline pre-treatment.

Figure 4: FT-IR analysis of a commercial xanthan sample (CX) and samples produced using the Passion Fruit Peel / Cheese Whey substrate hydrolysed using both the acid (AH:W) and basic (BH:W) methods. 


\section{Tables}

Table 1: Physicochemical characterization of the cheese whey and passion fruit peel used as a substrate for fermentation in the production of xanthan gum by strains of Xanthomonas campestris.

\begin{tabular}{l|c|c|c|c}
\hline \multicolumn{1}{c|}{ Analysis } & $\begin{array}{c}\text { Cheese } \\
\text { whey }\end{array}$ & $\begin{array}{c}\text { Passion fruit } \\
\text { peel }\end{array}$ & $\begin{array}{c}\text { Extract of the passion } \\
\text { fruit peel - acid (AH) }\end{array}$ & $\begin{array}{c}\text { Extract of the passion fruit } \\
\text { peel -alkaline (BH) }\end{array}$ \\
\hline $\mathrm{pH}$ & $6.58 \pm 0.34$ & $3,87 \pm 0.20$ & 2.00 & 6.00 \\
\hline Moisture (\%) & $93.70 \pm 0.42$ & $87.19 \pm 0.26$ & 98.26 & 98.46 \\
\hline Ash (\%) & $0.55 \pm 0.07$ & $6.94 \pm 0.15$ & 0.15 & 0.10 \\
\hline Crude protein (\%) & $0.82 \pm 0,02$ & $0.79 \pm 0.05$ & 0.14 & 0.12 \\
\hline Total lipids (\%) & $0.78 \pm 0.05$ & $0.03 \pm 0.01$ & $<0.01$ & $<0.01$ \\
\hline Carbohydrate (\%) & $4.15 \pm 0.08$ & $5.05 \pm 0.50$ & 1.52 & 0.04 \\
\hline $\mathrm{NaCl}(\%)$ & - & - & 0.02 & $<0.01$ \\
\hline $\mathrm{P}\left(\mathrm{mg} .100 \mathrm{~g}^{-1}\right)$ & 0.10 & - & $<0.01$ & 28.10 \\
\hline $\mathrm{Mg}\left({\left.\mathrm{mg} .100 \mathrm{~g}^{-1}\right)}_{\mathrm{K}\left(\mathrm{mg} .100 \mathrm{~g}^{-1}\right)}^{5.10}\right.$ & 110.32 & - & 29.10 & 22.30 \\
\hline
\end{tabular}


Table 2: Effect of the composition of the medium and the pre-treatment of hydrolyse fruit peel on rheological parameters of the Ostwald-de-Walle model fitted to the experimental data obtained in $3 \%(\mathrm{w} / \mathrm{v})$ xanthan gum solutions at $25^{\circ} \mathrm{C}$.

\begin{tabular}{|c|c|c|c|c|c|c|}
\hline & \multicolumn{6}{|c|}{ Rheological parameters } \\
\hline & & $\bar{n}$ & $\mathrm{~K}$ & $\mathrm{R}^{2}$ & $\mu(\mathrm{mPa} . \mathrm{s})$ & \\
\hline \multirow{3}{*}{ 总离芯 } & AH:W - Sucrose & 0.739 & 59.30 & 0.998 & 31.9 & 10.8 \\
\hline & AH:W - Phosphate & 0.486 & 1252.70 & 0.999 & 230 & 36.2 \\
\hline & $\mathrm{AH}: \mathrm{W}$ & 0.398 & 3579.20 & 0.999 & 510 & 56.9 \\
\hline \multirow{3}{*}{ 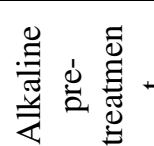 } & BH:W - Sucrose & 0.545 & 637.360 & 0.999 & 137 & 27.6 \\
\hline & BH:W - Phosphate & 0.501 & 1342.00 & 0.997 & 245 & 41.2 \\
\hline & BH:W & 0.488 & 1244.80 & 0.999 & 229 & 36.2 \\
\hline
\end{tabular}




\section{Figures}

\subsection{FIGURE 1}

(A)
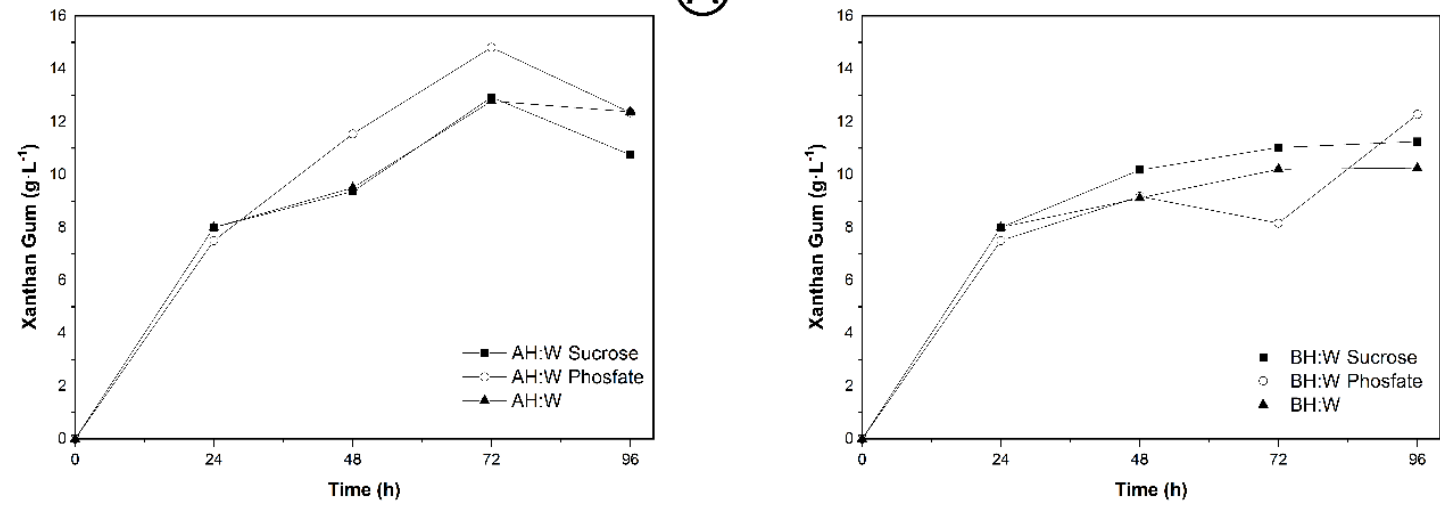

(B) 


\subsection{FIGURE 2}

(A)
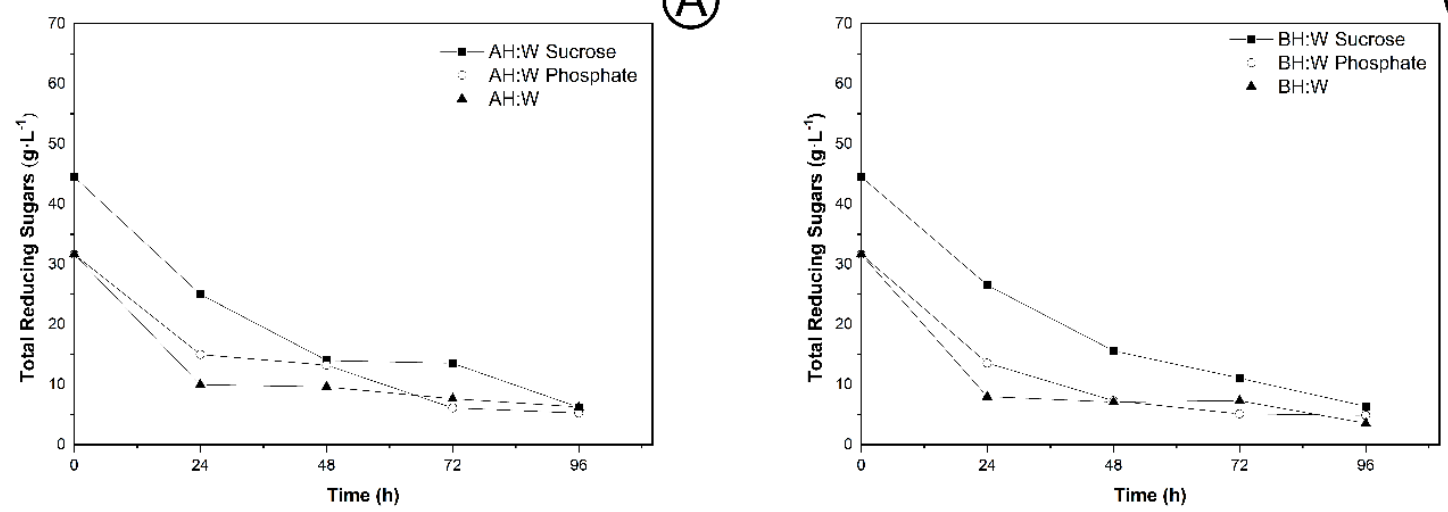

(C)

(B)

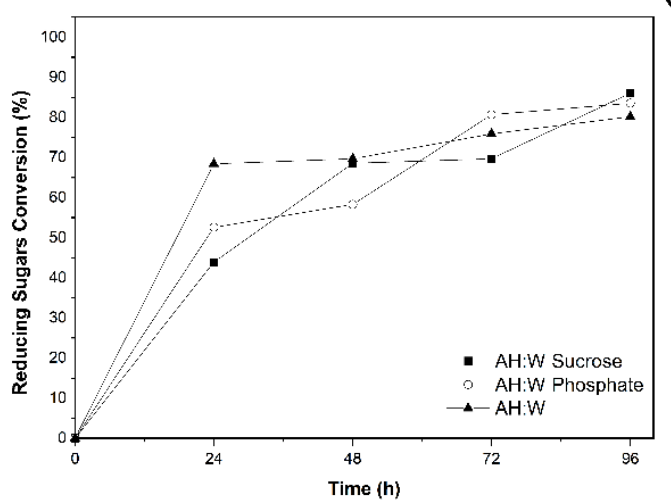

(D)

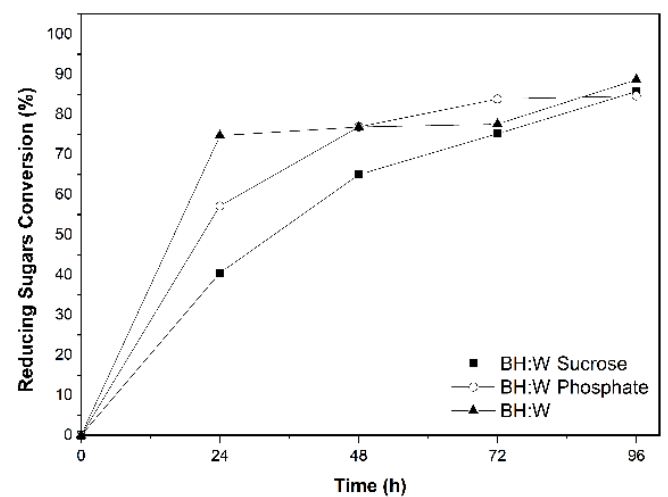




\subsection{FIGURE 3}

(A)
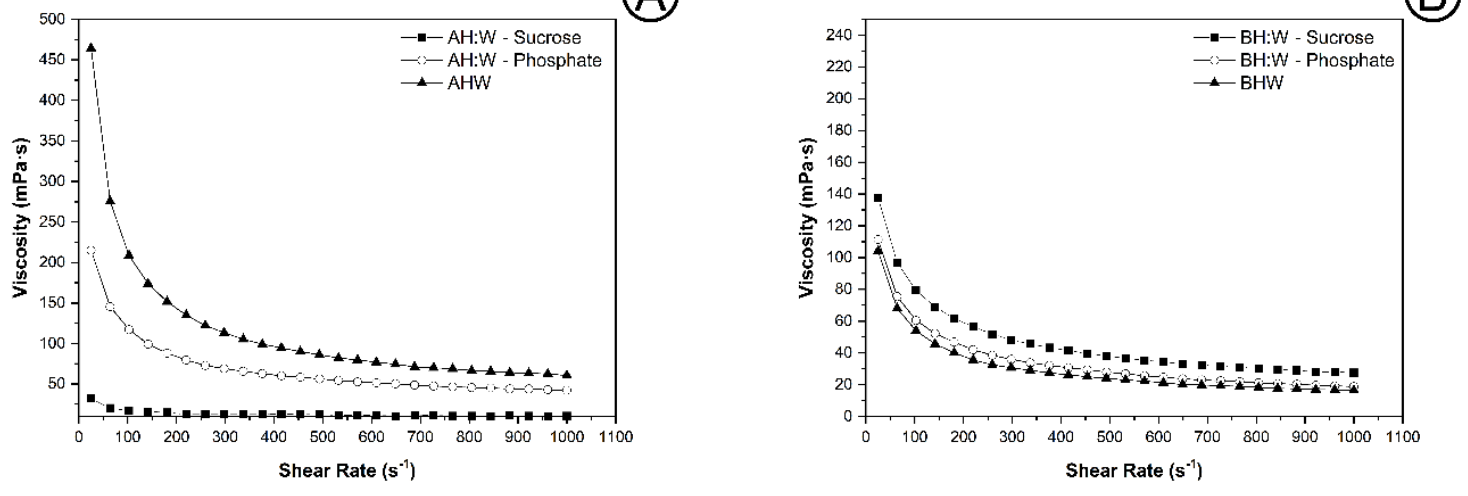


\subsection{FIGURE 4}

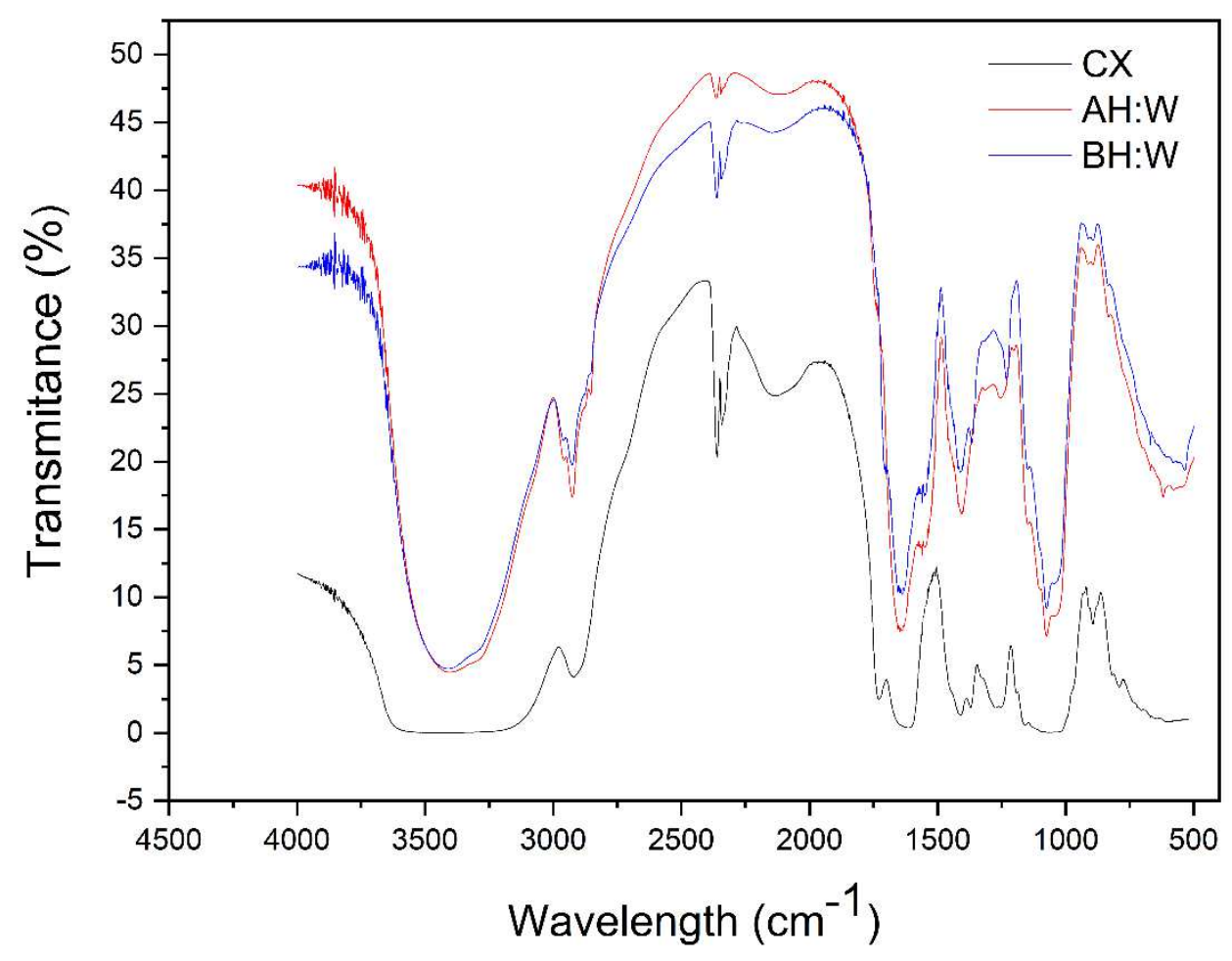


Figures

(A)
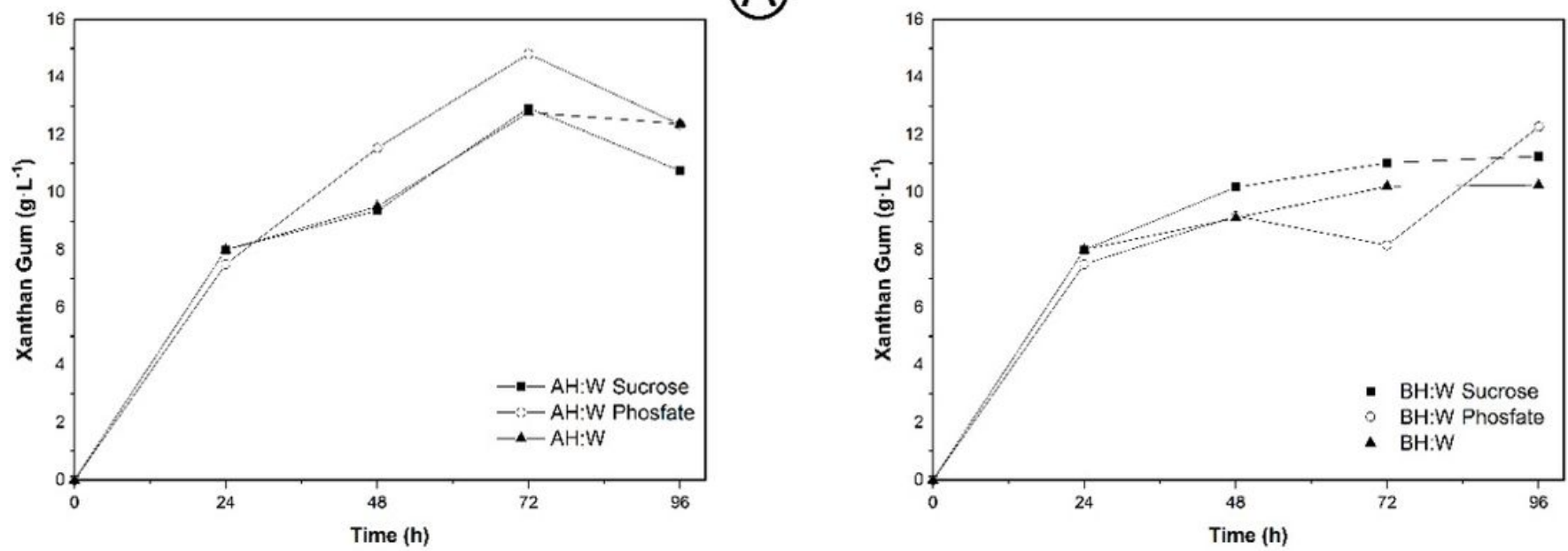

(B)

\section{Figure 1}

Effect of the supplementation of the medium and the pre-treatment of extract on xanthan gum production: acid hydrolysis (A) and alkaline hydrolysis (B). 
(A)
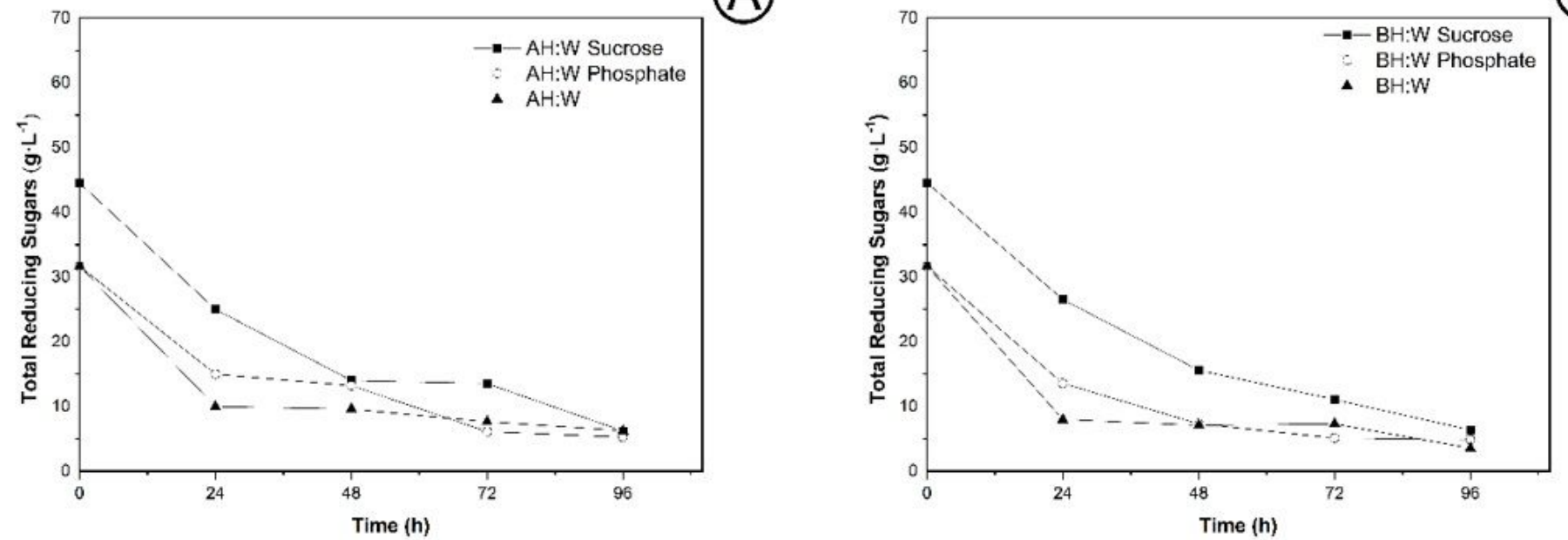

(C)

(B)
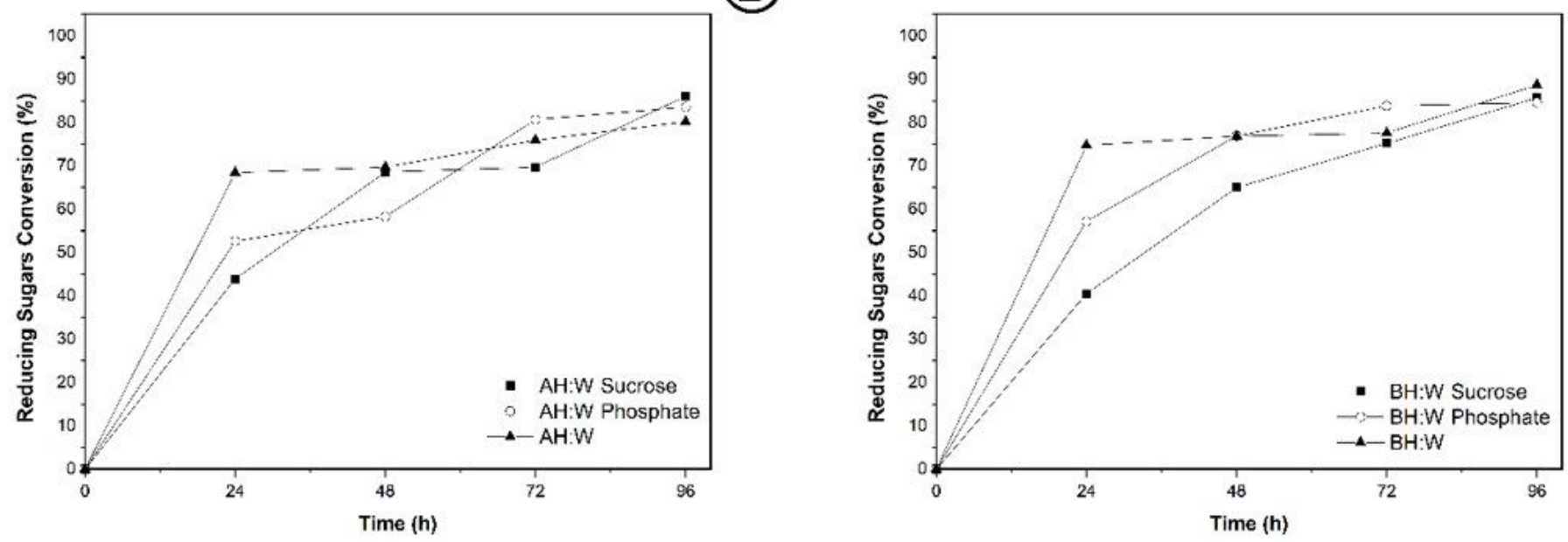

(D)

Figure 2

Effect of the supplementation of the medium and the pre-treatment of extract on total reducing sugars and reducing sugar conversion: acid - hydrolysis ( $A$ and $B$ ) and alkaline - hydrolysis ( $C$ and $D)$. 
(A)
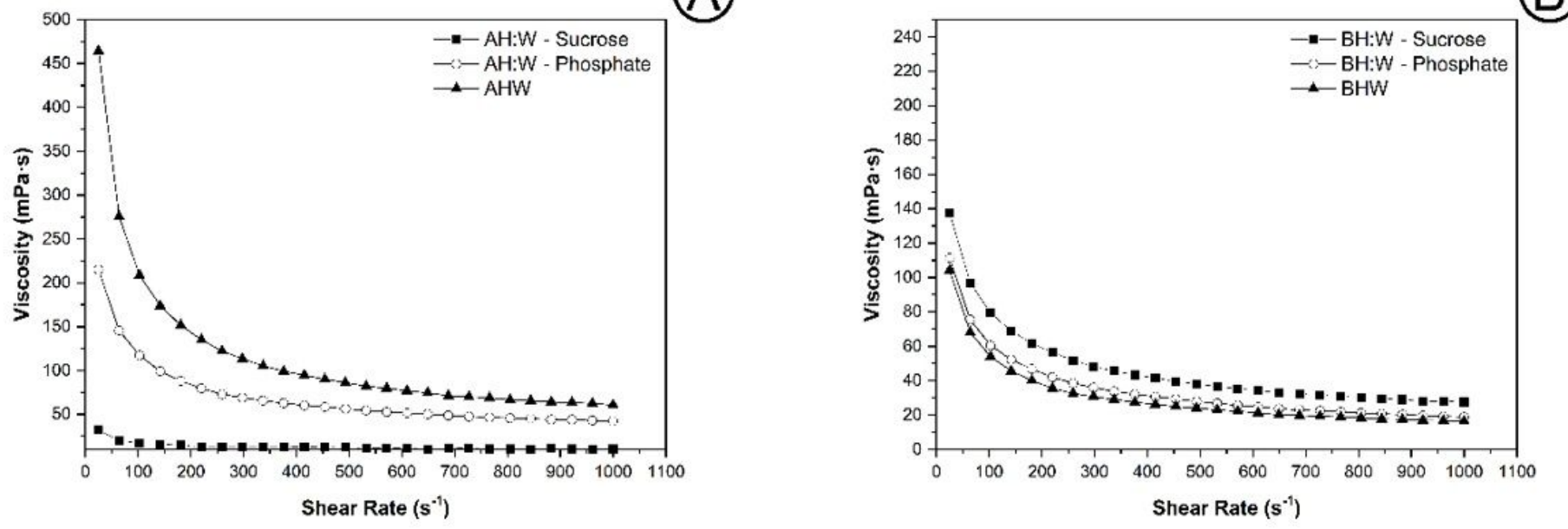

Figure 3

Effect of shear rate on the viscosity of the xanthan (A) acid pre-treatment and (B) alkaline pre-treatment. 


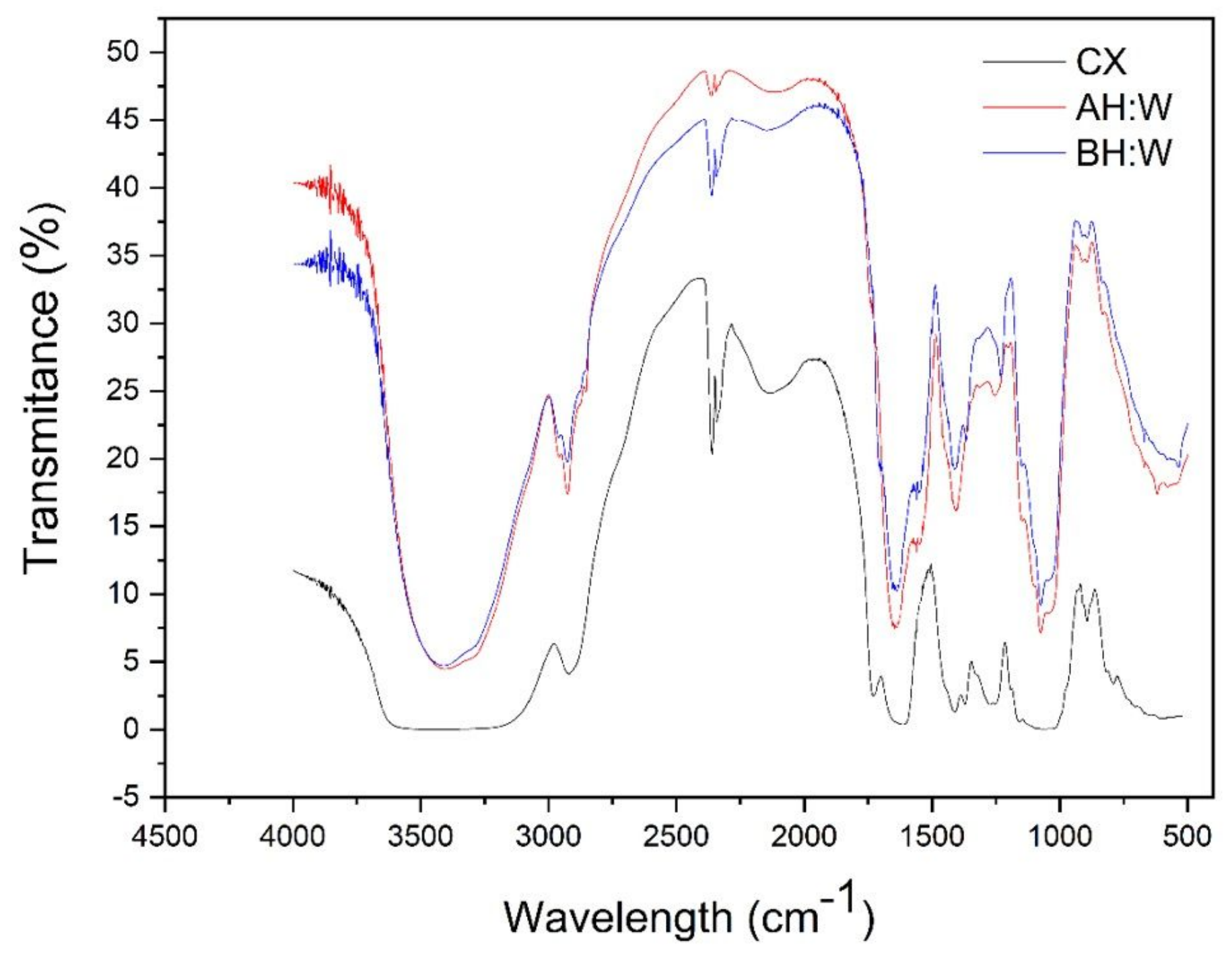

Figure 4

FT-IR analysis of a commercial xanthan sample (CX) and samples produced using the Passion Fruit Peel / Cheese Whey substrate hydrolysed using both the acid (AH:W) and basic (BH:W) methods. 